$\begin{array}{ll} & \text { Etnográfica } \\ \text { etnográfica } & \text { Revista do Centro em Rede de Investigação em }\end{array}$

Antropologia

vol. $23(2) \mid 2019$

Vol. $23(2)$

\title{
"Y nosotros, ¿qué ganamos?": identificaciones en el trabajo de campo etnográfico con cuadrillas juveniles en Costa Rica
}

"And what do we benefit?": identifications in ethnographic fieldwork with youth gangs in Costa Rica

Onésimo Rodríguez Aguilar

\section{(2) OpenEdition}

\section{Journals}

Edición electrónica

URL: https://journals.openedition.org/etnografica/6729

DOI: 10.4000/etnografica.6729

ISSN: 2182-2891

\section{Editor}

Centro em Rede de Investigação em Antropologia

Edición impresa

Fecha de publicación: 1 junio 2019

Paginación: 323-334

ISSN: 0873-6561

\section{Referencia electrónica}

Onésimo Rodríguez Aguilar, «"Y nosotros, ¿qué ganamos?”: identificaciones en el trabajo de campo etnográfico con cuadrillas juveniles en Costa Rica», Etnográfica [En línea], vol. 23 (2) | 2019, Publicado el 24 junio 2019, consultado el 19 enero 2022. URL: http://journals.openedition.org/etnografica/6729 ; DOI: https://doi.org/10.4000/etnografica.6729

\section{(c) (7) \&}

Etnográfica is licensed under a Creative Commons Attribution-NonCommercial 4.0 International License. 


\section{"Y nosotros, ¿qué ganamos?": identificaciones en el trabajo de campo etnográfico con cuadrillas juveniles en Costa Rica}

\section{Onésimo Rodríguez Aguilar}

El artículo se desprende de una investigación etnográfica realizada con integrantes de cuadrillas entre 2008 y 2009 en Guararí de Heredia: barrio urbano popular del Valle Central de Costa Rica (América Central). Algunas anécdotas etnográficas, vividas con estos jóvenes, me servirán para plantear una discusión en torno a la forma en que estos sujetos me identificaron durante mi trabajo de campo: siempre fui un extraño para ellos, papel que no imposibilitó la interacción etnográfica; es decir, decidí permanecer haciendo trabajo de campo con ellos, a pesar de dicha extrañeza.

PALABRAS-CLAVE: identificaciones, etnografía, cuadrillas, Guararí de Heredia, jóvenes, permanencia.

"And what do we benefit?": identifications in ethnographic fieldwork with youth gangs in Costa Rica - The article is based on an ethnographic research conducted with cuadrilla (gang) members between 2008 and 2009 in Guararí de Heredia, an urban and popular neighborhood in the Central Valley of Costa Rica (Central America). Two ethnographic anecdotes lived with these young people will serve to raise a discussion about the way these subjects identified me during my fieldwork: I was always an outsider to them, a role that did not preclude ethnographic interaction; that is to say, I decided to keep doing fieldwork with them, despite this strangeness.

KEYWORDS: identifications, ethnography, gangs, Guararí de Heredia, young people, permanence.

RODRÍGUEZ AGUILAR, Onésimo (onesimo.rodriguez@ucr.ac.cr) - Escuela de Antropología, Universidad de Costa Rica, Costa Rica. 


\section{INTRODUCCIÓN}

Este texto relata algunas historias etnográficas vividas con jóvenes en cuadrillas de Guararí de Heredia. ${ }^{1}$ Estas agrupaciones juveniles son social y mediáticamente conocidas como pandillas, aunque sus manifestaciones son diferentes. ${ }^{2}$

Se mostrará parte de la interacción que se mantuvo con personas pertenecientes a tres agrupaciones cuadrilleras: Los de la Finca, Los del Cole y Los de Villa Linda. ${ }^{3}$ Al respecto, es importante mencionar que estas asociaciones juveniles toman el nombre de sus respectivos sub-barrios (en Guararí existen varias ciudadelas, comunidades o sub-barrios) para autonombrarse, lo cual no es un dato menor, pues habla de la estrecha relación que existe entre estos grupos y su lugar de residencia.

El objetivo final de este recuento es evidenciar las diversas formas en que fui identificado durante mi trabajo de campo y, además, explicar cómo hice para permanecer haciendo etnografía con estos muchachos de orígenes, condiciones socioeconómicas y códigos morales diferentes de los míos. Intento reflexionar, desde el estatuto de extraño que varios de estos jóvenes me otorgaron pero que yo también propicié, no solo pensando en el porqué de estas atribuciones, sino tam-

l La investigación etnográfica fue realizada en el marco de la tesis doctoral del autor (Rodríguez Aguilar 2013) y una versión preliminar de este texto fue presentada en las VIII Jornadas de Etnografía y Métodos Cualitativos (celebradas del 10 al 12 de agosto de 2016), organizadas por el Centro de Antropología Social (CAS) del Instituto de Desarrollo Económico y Social (IDES), Buenos Aires, Argentina. A manera de contexto, es importante ofrecer algunos datos generales sobre Costa Rica. Según proyecciones del Instituto Nacional de Estadística y Censos (INEC), Costa Rica alcanzaría los 5.000.000 de habitantes en marzo de 2018 (Chinchilla 2017). Un 20\% de la población vive en condiciones de pobreza, mientras que un 5,7\% lo hace en pobreza extrema (Leitón 2017). La violencia social en el país ha sido un problema que ha ido en paulatino incremento; por ejemplo, para el 2017 se registraron más de 600 homicidios, una tasa de 12 por cada 100.000 habitantes; después de 10 se cataloga como epidemia, según la Organización Mundial de la Salud (OMS). La gran mayoría de estos asesinatos (70\%) se deben, según el Ministerio de Seguridad, a situaciones relacionadas con el narcotráfico/narcomenudeo (Solano 2017; Fallas 2017). En relación a la democracia, según una medición hecha por The Economist Intelligence Unit, Costa Rica se ubica como la segunda nación de América Latina en el "índice de democracia 2017". A pesar de estar entre los primeros puestos, "el país fue catalogado como democracia con defectos", puesto que "no alcanzó un puntaje superior a 8". De hecho, en Latinoamérica, "solo Uruguay fue nombrada como una democracia completa" (Barquero 2018). Estos breves datos contradicen la idea mítica con la que se ha construido Costa Rica: país de paz y pacifista y con una democracia infranqueable. Algunos investigadores han puesto entre dicho este imaginario nacional que ha trascendido fronteras; al respecto, ver Jiménez (2002), Molina (2003) y Sandoval (2006).

2 En otra parte (Rodríguez Aguilar 2013, 2017), antepongo la idea de "cuadrilla" a la de "pandilla" para referirme a jóvenes que integran agrupaciones informales en barrios urbano-populares cuya ética dista de las dinámicas pandilleras, fundamentalmente en lo referido a la organización y al uso de la violencia (los medios de comunicación y ciertos sectores de la opinión pública han querido asimilar las cuadrillas con las "maras" del norte centroamericano). Además, "cuadrilla" es un término empleado por los propios jóvenes (categoría "nativa”), el cual está distante de las consideraciones estigmatizadas que recaen sobre la categoría "pandilla".

3 Todos los nombres aparecidos en este texto han sido modificados. 
bién en qué tienen que ver con mi práctica antropológica y qué dicen sobre las propias existencias de los sujetos. En fin, pretendo develar algunas posibles situaciones que pueden acontecer durante la puesta en escena etnográfica, esto es, cuando intentamos aprehender el sentido que los sujetos le dan a sus prácticas.

\section{"Y NOSOTROS, ¿QUÉ GANAMOS?"}

Muchas cosas pasaron durante mi estancia etnográfica en Guararí (diciembre de 2008 a julio de 2009). ${ }^{4}$ En este escrito me interesa rescatar algunos fragmentos vivenciales de cómo fui identificado y recibido durante dicha implementación.

El primer acercamiento que tuve con una cuadrilla se dio una tarde de lunes del mes de diciembre de 2008. Aquella vez intenté conversar con un joven que llamaré Pérez; él estaba apostado en una de las esquinas de Villa Linda con otros muchachos de la agrupación.

Yo le había solicitado a don Elmer, vecino y líder de la lucha pro-vivienda del lugar (a quien ya conocía de un proceso de investigación anterior), que me acompañara. Pensé que su compañía resultaría ser bien vista por los jóvenes. Al final, esta estrategia fue un desacierto metodológico. ${ }^{5}$ Los jóvenes no lo querían, porque varias veces se habían suscitado tensiones y enfrentamientos entre ellos y el líder comunal. Evidentemente, yo llegué a conocer estos hechos tiempo después.

Aquel lunes empecé a conversar con ellos, habiendo sido previamente presentado por don Elmer. Les hablaba de mis intenciones en el lugar: hacer mi tesis sobre sus vidas, refutar versiones mediáticas estigmatizantes, mostrar una cara distinta de ellos mismos y de Guararí, etcétera.

4 Guararí es un barrio popular, creado a mediados de 1980. Antes de este tiempo era una finca cafetalera, la cual, gracias a una ocupación de personas provenientes de sectores urbanos y rurales del país, empezó a ser habitada. Paulatinamente, se fueron construyendo diversos proyectos de vivienda (auspiciados por el Estado costarricense), gracias al esfuerzo y lucha de los y las residentes de la ciudadela. Varios de los sectores del barrio están constituidos por viviendas informales (llamados "tugurios" en Costa Rica): casas de latas (zinc) y restos de madera, en muy malas condiciones. Villa Paola, para el tiempo de la implementación etnográfica, era una zona de viviendas informales. Para finales del 2009, un proyecto de vivienda dotó de "casa digna" a las personas que ahí vivían (Rodríguez Aguilar 2017).

5 Rosana Guber, acerca de estos desaciertos, plantea: "suele creerse que los hechos disruptivos obedecen a errores o a 'metidas de pata'. De las contribuciones que leemos aquí debiera quedar claro que errores y aciertos permean la totalidad de situaciones por las que transcurre nuestra persona de investigadoras. Pero más allá de cierta sospecha bastante general, no existe ningún código prescripto donde conste qué es error y qué es acierto en esa situación puntual, hasta la hora de cometerlo. El buen trabajo de campo, por lo complejo, cabal y auténtico, se desarrolla en base a la práctica, a la ignorancia informada y sensible, y a la imperiosa toma de decisiones pequeñas, de poca vistosidad académica y de gran significación humana" (2014: 32). Cometí muchos errores, queriendo o sin querer, de pequeña y gran envergadura, pero las posibilidades analíticas y de comprensión de esos mundos a partir de esos desaciertos fueron significativas, tanto que me abrieron ventanas reflexivas que posibilitaron otras formas de entrada y permanencia en el campo. 
Pérez se levantó de su lugar y me interrumpió: “iAhhhh!”, mientras me increpaba sacando su pecho frente a mí en señal de confrontación. "¿Usted lo que quiere es sacarnos información para su tesis y después irse, usarnos como conejillos de indias? Y nosotros, ¿qué ganamos con eso que usted quiere hacer? Véanos", mientras señalaba a sus amigos, "somos unas ratas". ${ }^{6}$

Yo no pude contestar nada. La demanda del muchacho me llamó tan poderosamente la atención que no supe cómo reaccionar. Estaba realmente incómodo. Después de algunos minutos atiné a despedirme y retirarme de la esquina con don Elmer. "Bueno maes, nos estamos viendo", dije, optimista. "Tuanis, rata", respondieron algunos.

"Somos unas ratas", en aquel contexto, significaba que no había nada que yo pudiera decir sobre ellos más que eran malos, ellos no eran buenos, y al parecer, según Pérez, no querían serlo. Quizás Pérez no estaba interesado en que yo dijera nada diferente a lo que él ya sabía o creía que eran, ¿qué podría decir yo sobre ellos que ellos mismos desconocieran? ¿Quién era yo para intentar decir algo "bueno" o "malo" sobre ellos?

Esta historia puede ser contrastada con otra ocurrida en la misma ciudadela, un par de meses después, cuando fui invitado, por doña Ana, señora integrante de un grupo de madres de la localidad, a una reunión comunal que se llevaría a cabo por aquellos días en una de las viviendas informales.

Habiendo aceptado la invitación, llegué al lugar - el día en cuestión - a eso de las 7 de la tarde. Fuí recibido de manera muy cordial por doña Ana. En el lugar estaban las señoras integrantes del grupo de madres y sus hijos, jóvenes, varios de ellos, pertenecientes a la cuadrilla de Villa Linda. Al menos tres de estos muchachos estuvieron presentes aquel día en que Perez me increpó. Estaban sentados en una de las bancas, yo saludé y ellos me saludaron. Había carne asada y algunos refrescos que yo podía consumir a cambio de una módica suma. Lo recaudado, según me dijeron, iría en beneficio de la asociación de madres.

Doña Ana, en algún momento de la noche, se me acercó y me dijo: “iLes podría decir algunas palabras a ellos?” Con la mirada, me señaló a los jóvenes que estaban sentados en una de las bancas. Yo en realidad no entendía, por lo cual le pregunté a la señora: “¿Qué les digo?" "No sé, hábleles de las drogas y el alcohol y todo eso, para que ellos entiendan".

Tras mi pánico escénico inicial pude decir algunas palabras para no contrariar la voluntad de la señora. No me acuerdo qué exactamente les dije, pero me sentí realmente incómodo, hablándole a un grupo de jóvenes sobre sus problemas de adicción, como si yo fuera un personero del IAFA (Instituto sobre

6 "Ratas" responde a un término muy usual en las cuadrillas, el cual refiere a la "ley del más malo" (Abarca y Sepúlveda 2005), es decir, mientras más malo se es, más respecto y honor se posee. Es una especie de inversión ideológica de la maldad. Además, las ratas (roedores) sobreviven. Muchos de estos jóvenes intentan sobrevivir todos los días a diferentes y profundas contradicciones. 
Alcoholismo y Fármaco Dependencia). Al final les recomendé, a ellos y a sus madres, quienes estaban muy concentradas escuchando lo que yo decía, llamar a esta institución o a alguna agencia gubernamental para buscar ayuda.

Después de mi intervención, uno de los jóvenes se me acercó, él estaba realmente intoxicado y no podía quedarse en pie. Con cara de sufrimiento, me dijo: “AAyúdeme, mae, vea como estoy... Ayúdeme!" Yo, contrariado y angustiado, volví a repetirle el consejo que había dado anteriormente, y le dije que si él quería le ayudaba a buscar los contactos en las agencias del gobierno; en realidad le dije esto también a su mamá, quién se me acercó luego para saber qué había conversado con el hijo. Al día siguiente en la mañana, ella me llamó para coordinar cómo procederíamos.

Debido a mi incomodidad en ambas situaciones (con Pérez y en la reunión organizada por el grupo de madres), y a lo que yo entendí como una confusión de los sujetos sobre mi estatuto, decidí no continuar haciendo trabajo de campo con esta cuadrilla. No quería ser identificado como extraño/enemigo o como asistencialista (en la parte final de este documento, haré una síntesis analítica acerca de estas dos vivencias ocurridas en el barrio; por lo pronto, describiré otra de las historias).

\section{"MAE, ¿USTED ES DE LA LEY?"}

Para marzo de 2009, después de casi tres meses de estar interactuando con los muchachos de La Finca, durante una de las noches en que me encontraba en el lugar, Sofi (la única mujer cuadrillera de las agrupaciones con las cuales trabajé), me comentaba que algunos de los miembros de la agrupación me tenían desconfianza porque pensaban que yo era del Organismo de Investigación Judicial (OIJ). ${ }^{7}$ Después de dicha confesión me sentí frustrado y ansioso, ¿cómo iba a ser posible que, después de tres meses, existiesen dudas acerca de mi procedencia?

A pesar de mi frustración, me pude reponer. Dos noches después volví a La Finca. Me encontré con un grupo nutrido de jóvenes, unos 25 muchachos ubicados en las afueras del súper del "chino" (minisúper, tienda o comercial pequeño). Un muchacho a quién llamaré Alfonso me saludó y al enterarse de que yo venía de Guararí, de "pasar el rato" con otra cuadrilla, me dijo: "iPero usted tiene compas por todo lado! Mejor quédese aquí con nosotros, la gente de Guararí nada que ver".

La demanda del chico estaba cargada de empatía, lo que se había puesto en duda tan sólo dos días atrás. ${ }^{8}$ Instantes después, cuando sentía un alivio interno

$7 \quad$ Tiempo después uno de los muchachos me comentó que un amigo de la cuadrilla se encontraba preso por venta de drogas; al parecer, un infiltrado del OIJ lo delató.

8 Cuando se sospechó de mi procedencia, este muchacho no estaba presente hacia dos noches. 
en vista de las palabras de Alfonso, otro joven, Ernesto, me interpela con un gesto de confrontación, aunque con un sutil tono de broma (de quien sabe que mi posición en la cuadrilla no le afecta): "Mae, a mí no me importa que ande con quien quiera, sólo dígame una cosa, ¿usted es de la ley?" Ahí, delante de todos esos jóvenes dije: "iNo! Por mi padre que tiene 10 años de muerto".

Días después, al llegar a La Finca para continuar con mi trabajo en la zona, otro de los jóvenes, Montiel, quien no había estado la noche en la que Ernesto cuestionaba mi procedencia, me hizo la misma pregunta: “¿Usted es de la policía?” El tono de este joven fue más relajado, como haciendo una pregunta sobre la cual ya conocía la respuesta. Andrés y Mori, que sí habían estado presentes la noche en la que me defendí con la mención de la muerte de mi padre, le dijeron: "No sea necio mae, ya el mae dijo que nada que ver con esa vara, deje de joder". "Bueno, bueno, está bien, tranquilos, solo quería saber", expresó Montiel, algo sorprendido por la reacción de sus amigos. Nunca más, que yo me diera cuenta, se volvió a tocar el tema de mi procedencia.

Después de la defensa de Andrés y Mori delante de uno de los suyos, me sentí reconfortado, aunque mi condición de extraño persistía. Esta situación se iba a mantener con otros grupos de jóvenes de Guararí, como quedará manifiesto en la siguiente anécdota.

\section{UN “HERMAN DEMASIADO HONESTO”}

Algún tiempo después de estas experiencias, ya entrado el mes de junio de 2009, sucedieron algunas situaciones interesantes en mi interacción con otra cuadrilla juvenil de la zona. Tenía aproximadamente cuatro meses de estar compartiendo con la cuadrilla de Los del Cole. Ellos frecuentaban todas las noches las afueras del colegio nocturno de Guararí (secundaria). Pude contactar a este grupo gracias a Fabricio, uno de los líderes de La Ultra Morada ${ }^{9}$ y viejo amigo que conocí durante un trabajo de campo previo que realicé con jóvenes de las barras organizadas de fútbol en Costa Rica.

Uno de los muchachos, a quien llamaré Tito, durante una de las noches en que llegué al barrio, me recibió, en tono chistoso, con un saludo y un apodo: “¿Qué me dice, Herman?”, en referencia al personaje de televisión protagonista de The Munster (serie de mediados de 1960). Yo le respondí el saludo; inmediatamente le pregunté: “¿Por qué Herman?” "Mae, es que usted tiene la cara cuadrada y es así, grande [en referencia a mi estatura y contextura corporal]".

En otra ocasión, otro de los muchachos de esa cuadrilla, de nombre Memo, me llamó "Demasiado honesto", haciendo alusión a un personaje de un programa de televisión nacional que se caracteriza por ser, precisamente muy

9 Barra organizada/hinchada/torcida, que apoya al Deportivo Saprissa, S. A. Club de Primera División del fútbol de Costa Rica. 
honesto. Este apodo me lo adjudicó este joven después de un viaje que hice con ellos al Pacífico Sur de Costa Rica. Recuerdo que cuando llegué a la casa de uno de los muchachos a ultimar detalles para irnos para la playa (el viaje referido), en la mesa había una cantidad considerable de marihuana ordenada en cigarrillos. Yo pregunté: “¿Por qué tanta mecha, maes?” La respuesta de Tito: "Diay compa, para vender y así”.

Íbamos en el carro de mi hermana, se lo pedí prestado para la ocasión. Dos de los muchachos eran menores de edad. Me dije a mí mismo: "Si nos llegara a pescar [detener] la policía, me acusarían de corrupción de menores y, además, de tráfico de drogas, imínimo 20 años de cárcel por hacer etnografía!" Sentí ganas de irme del lugar, marcharme sin decir nada; claro, esta acción hubiese significado el fin de mi trabajo de campo con estos jóvenes. Decidí continuar mi trayecto con los muchachos.

Horas después, habiendo superado el impacto que me causó aquella situación angustiosa, encontrados en la playa, los muchachos deciden ir al supermercado de la localidad. La intención, de la cual no me di cuenta hasta que estábamos en el establecimiento, era sustraer algunos objetos (cremas, bronceadores y bloqueadores) para después venderlos (yo, incluso, les compré algunos de esos productos).

Ocultaban lo sustraído entre sus genitales y sus ropas para poder sacarlos del comercial. El primer día los acompañé, pero me puse tan nervioso que por un momento pensé en que mi ansiedad los iba a delatar. Decidí quedarme un poco alejado de ellos, como defensa, pero, ante todo, por miedo. Para las subsiguientes experiencias en el "súper", Fabricio me recomendó que me quedara en el carro esperándolos, me dijo: "Mae, mejor quédese en el carro, nosotros entramos y salimos rápido".

Mis reacciones, ante dinámicas naturalizadas por el habitus cuadrillero, hicieron posible la designación de "Demasiado honesto"; claro, eran dos moralidades naturalizadas, dos formas de entender dichas prácticas que chocaban y se tensionaban.

La forma brillante, dispuesta por Fabricio, de solucionar la disputa moral fue alejarme de lo que para mí significaba un terreno de ansiedad; él, en aquel momento, entendió, mucho mejor que yo, los sentidos que cada uno de nosotros dábamos a las situaciones referidas.

PARA CONCLUIR: "Y NOSOTROS, ¿QUÉ GANAMOS CON EL POLICÍA, 'HERMAN' Y 'DEMASIADO HONESTO' "?

Intentaré detenerme analíticamente en estas historias. Empezaré por la última. Los apodos "Herman" y "Demasiado honesto" llaman la atención sobre la condición de extraño que tuve en las cuadrillas. Ellos me recibían, viajábamos a distintos lugares, bromeaban conmigo, incluso disentíamos en algunas 
conversaciones, pero los sobrenombres que me pusieron muestran que yo era, de alguna forma, un individuo lejano a sus especificidades cotidianas y que por más que quisiera no iba a introyectar o corporizar ciertos códigos morales que para ellos eran básicos, naturales.

Hermitte nos dice:

“En esa etapa inicial la presencia del antropólogo en la comunidad se caracteriza por una gran visibilidad. No es un miembro de ella sino un forastero que, no obstante, se acerca a la gente, conversa, pregunta, y trata de participar en los eventos comunales, sean éstos de carácter cotidiano o esporádico. Quién es y qué hace allí son dos interrogantes que se plantean los naturales del lugar y que el trabajador de campo debe responder" (2002: 217-218).

Estoy de acuerdo con Hermitte (2002) en el estatuto de forastero del etnógrafo y sus implicancias; máxime cuando, retomando a Nash (1963), esgrime "el antropólogo en su trabajo de campo es un extraño que debe enfrentarse al problema de adaptarse a ese rol" y que este extrañamiento "prevalecerá hasta que adquiera las cualidades necesarias del grupo, es decir un marco de referencia aceptable y un número de formas de conducta que le permitan ser un miembro regular y bien conceptuado hasta que deje la comunidad" (Hermitte 2002: 231 ).

Yo fui aceptado por estos jóvenes, pero nunca me sentí totalmente incluido. Como dice Hermitte (2002), me adapté al rol de extraño y pude comprender algunas cualidades del grupo que me permitieron permanecer en él.

Ahora, pienso que esta permanencia dentro del grupo se debió a un estatuto particular: fui un "extraño habitual". A diferencia de Hermitte, creo que no solo se trata de comprender las cualidades del grupo para ser "bien conceptuado", es también necesario que el grupo comprenda las cualidades de uno (como bien lo hicieron los jóvenes con los apodos referidos), para así, a pesar de las tensiones morales que puedan emerger, ocupar un lugar en el espacio de sus vivencias colectivas. Intento decir, con Guber (2008, 2014), que la reflexividad es invariablemente mutua: tanto nosotros como ellos nos incorporamos a dinámicas de reflexión, nos ubicamos en ciertos lugares y decidimos si queremos continuar o no, habiendo meditado y valorado múltiples situaciones. Integramos, al fin, una trama compleja, que es posible solamente gracias a la (des)unión de esas subjetividades, en ocasiones, disímiles.

Con la cuadrilla de Villa Linda no hubo permanencia etnográfica. Abandoné la interacción después de lo acontecido con Pérez y la reunión organizada por las madres de estos muchachos. En aquella ocasión, hui de ellos. Pero esta vez quisiera quedarme y repensar aquella frase: "Usted hace su tesis y nosotros ¿qué ganamos? Véanos, somos unas ratas". 
La petitoria de Pérez, al parecer material, no solo era una demanda. Como decía más arriba, me increpaba por pensar en la posibilidad de poder decir algo "bueno" de ellos, siendo que, según él, querían mantener el estatuto de "ratas", de malos, pues es la forma que han ideado para sobrevivir en un contexto desigual y con muchísimas carencias. Para él, yo en mi estatuto de forastero no podía comprender la situación en la que se encontraban. Hay que recordar que fue la primera vez que intenté acercarme a esta cuadrilla y además lo hice acompañado de un líder que ellos no querían.

Entre tanto, el "iayúdeme, mae!" del joven alcohólico era una demanda distinta de la de Pérez: ahí sí, para él, yo podía comprender su situación. Recuérdese que a aquella actividad fui invitado por una de las madres (incluso fui recibido por ella); en consecuencia, mi condición en el lugar cambiaba. De nuevo: un "extraño habitual".

El punto es que, en ambas situaciones, durante mi trabajo de campo, yo me sentí similar: incómodo y fuera de lugar, porque no podían verme en mi calidad de investigador (i ¿qué es ser investigador para ellos?!). No pude disociar una situación de la otra.

Hoy pienso que no tenía mucha trascendencia la forma en que inicialmente me identificaran (como tiempo después no me importó significativamente que Los del Cole me dijeran "Herman" o "Muy Honesto", o bien, que pudiera seguir con Los de la Finca a pesar de su desconfianza en torno a mi procedencia). Me iban a identificar con cualquier cosa o personaje que fuera familiar para ellos, menos como antropólogo, oficio disciplinar que desconocen (y que no tienen por qué conocer).

El asunto es que, con el mismo grupo con el que semanas antes había ocurrido el evento de la demanda "¿Usted hace su tesis y nosotros qué ganamos?", se abrió un vínculo que yo decidí obviar; quizás porque, como dice Markowitz (2003), citado en Guber, Milstein y Schiavoni (2014: 53), "lo que los antropólogos desean en el trabajo de campo es intimidad, pero es también lo que más temen".

Ahora bien, más allá de lo anterior, las palabras de Pérez también cuestionan lo que en nuestro papel de etnógrafos estamos en posibilidades de ofrecer.

Para Geertz, "lo único que uno tiene que dar realmente para evitar la mendicidad (o - para no pasar por alto el método de las chucherías y los abalorios el soborno) es así mismo" es decir, "convertirse en alguien apreciable para nuestros informantes - esto es, un amigo - para mantener el propio respeto" (1996: 53). Geertz no era ingenuo al respecto; sabía que existía una "asimetría moral inherente a la situación del trabajo de campo" y, por ende, "un conjunto de ficciones parciales reconocidas solo a medias", de forma tal que, en dichas circunstancias, "la relación progresa suficientemente bien"; así, el antropólogo "se mantiene por el valor científico de los datos" (1996: 54), mientras que, en el informante, 
"el interés se mantiene vivo gracias a toda una serie de conquistas secundarias; la sensación de ser un colaborador esencial en una empresa importante, aunque apenas comprendida; el orgullo de su propia cultura y de su conocimiento experto de la misma; la oportunidad de expresar ideas y opiniones personales (y de contar chismes) a un oyente neutral y externo; así como, de nuevo, una cierta cantidad de beneficios materiales directos e indirectos de uno u otro tipo" (Geertz 1996: 54).

Pareciera estar clara la razón fundamental por la cual uno decide permanecer. Pero, en fórmula algo distinta a la autoridad, unilateralidad y prepotencia geertziana, es preciso señalar con Guber, Milstein y Schiavoni que, en esta relación con los sujetos, "siempre habría algo a cambio, aunque fuera un rato de conversación en los causes del afecto y del respeto" (2014: 55), lo cual supone cierta bilateralidad en la conversación, ausente en el autor del "juego profundo".

Nuestra permanencia en campo exige un esfuerzo por tomar algunas pequeñas decisiones que podrían ser de gran significación, como lo apuntaba algunos párrafos arriba. Y no es que estos esfuerzos y estas decisiones estén planeadas o estén consideradas dentro del marco lógico de una propuesta etnográfica. Lo que sucede es una serie de situaciones espontáneas, sobre las cuales vale más implementar el sentido común que alguna "gran estrategia" incluida en los manuales de cómo hacer "buena etnografía" - me sucedió cuando mencioné la figura de mi padre fallecido para dar credibilidad a mi estatuto de investigador/ antropólogo y poder demostrar que no era policía, como lo suponía Ernesto -

Berreman (1962), en su estudio clásico sobre los Sirkanda del Bajo Himalaya al norte de India, detalla cómo fue el trabajo de campo en dicha sociedad donde se solía ignorar a los forasteros. Una de las razones para que los lugareños se comportasen así es que su única relación con personas foráneas estaba limitada, al igual que muchos de los jóvenes en cuadrillas de Guararí, al contacto con policías y agentes impositivos; en consecuencia, cualquier extranjero podía ser "agente del gobierno" y "como tal, potencialmente problemático, e incluso peligroso" (1962: 5). Los nativos ocultaban una serie de prácticas extranormativas que no querían que fueran develadas, de ahí su miedo particular a los "extraños" (situación similar me sucedió con las cuadrillas). Como era de esperar, el etnógrafo Berreman y sus colaboradores fueron sospechosos de tener segundas intenciones mientras se desarrollaba el trabajo de campo. Aun así, a los pocos meses, según el relato del autor, pudieron, él y su equipo, trascender esa imagen de extraños y entablar comunicaciones con los lugareños, eso sí, sin que mediara, como en otros textos etnográficos, leyendas extraordinarias de rapport (Geertz 1989).

Esto llama poderosamente la atención, pues, tal como con las vivencias con jóvenes que he descrito, fue el proceso cotidiano de convivio el que hizo 
posible la compenetración con algunos de ellos y que paulatinamente fue exorcizando la imagen que yo les proyectaba (policía, enemigo).

Para Berreman (1962), la permanencia es un asunto de disposición; yo agregaría que también tiene que ver con la disposición de ellos y ellas (los y las nativos/ as); como mencioné antes, resulta de un esfuerzo mutuo por comprender los estatutos que rigen la lógica moral y cultural de ambas subjetividades. En nuestro caso, como etnógrafos, no para ser como ellos, sino para intentar no transgredir de entrada esos valores que suelen ser importantísimos y, claro, para no asumir ciertas interpretaciones erradas, como me sucedió el día de la "reunión de las madres". En el caso de ellos, para poder hacerse una idea de ese extraño que aborda sus cotidianidades y definir si pueden, de alguna u otra forma, confiar en él.

Entonces, es sumamente sugerente que, durante mi proceso de trabajo de campo, estos jóvenes me hicieran preguntas directas acerca de si yo era policía o no, que me confrontaran haciéndome ver que yo no iba a decirles nada nuevo sobre ellos mismos pues eran y seguirían siendo "ratas", incluso que me pusieran sobrenombres. Ellos, según creo, me ponían a prueba y lo hacían porque finalmente estaban en una posición que les permitía ubicarme en ese tipo de situaciones.

Ellos querían saber con certeza quien era yo y yo, por mi parte, estaba muy interesado en demostrar que era quien decía que era; en ese juego de comprobaciones de autenticidades, las ansiedades de unos y otros, incluyéndome, emergen, pero emergen porque así son las relaciones sociales: una vorágine, a veces inusitada, de situaciones que suceden debido a la propia indecifrabilidad total de las interacciones humanas.

\section{BIBLIOGRAFÍA}

ABARCA, Humberto, y Mauricio SEPÚLVEDA, 2005, "Barras bravas, pasión guerrera: territorio, masculinidad y violencia en el fútbol chileno”, en Francisco Ferrándiz y Carles Feixa (comps.), Jóvenes Sin Tregua: Cultura y Políticas de la Violencia. Barcelona, Anthropos, 145-169.

BARQUERO, Karla, 2018, “Costa Rica, líder en democracia de Centroamérica”, en LaRepública.net, 12 de febrero, disponible en < https://www.larepublica.net/noticia/costa-rica-lider-en-democracia-de-centroamerica > (última consulta en junio de 2019).

BERREMAN, Gerald D., 1962, Behind Many Masks: Ethnography and Impression Management in a Himalayan Village. Ithaca, NY, The Society for Applied Anthropology.

CHINCHILLA, Sofía, 2017, "El tico 5 millones nacerá en marzo de 2018”, La Nación, 2 de abril, disponible en < https://www.nacion.com/el-pais/el-tico-5-millones-nacera-en-marzo-del-201 8/IVURKMXZEZAITGSWETA2G37SSM/story/ > (última consulta en junio de 2019). 
FALLAS, Gustavo, 2017, "Costa Rica camina hacia tasa más elevada de asesinatos", La Nación, 30 de junio, disponible en < https:/www.nacion.com/sucesos/crimenes/costarica-camina-hacia-tasa-mas-elevada-de-asesinatos/AA2VTK3WNJFDRM67GCT3NV33SA/ story/> (última consulta en junio de 2019).

GEERTZ, Clifford, 1989, La Interpretación de las Culturas. Barcelona, Gedisa.

GEERTZ, Clifford, 1996, Los Usos de la Diversidad. Barcelona, Paidós.

GUBER, Rosana, 2008, El Salvaje Metropolitano: Reconstrucción del Conocimiento Social en el Trabajo de Campo. Buenos Aires, Paidós.

GUBER, Rosana, 2014, “Introducción”, en R. Guber (comp.), Prácticas Etnográficas: Ejercicios de Reflexividad de Antropólogas de Campo. Buenos Aires, Miño y Dávila Editores, 13-40.

GUBER, Rosana, Diana MILSTEIN, y Lidia SCHIAVONI, 2014, "La reflexividad o el análisis de datos: tres antropólogas de campo", en R. Guber (comp.), Prácticas Etnográficas: Ejercicios de Reflexividad de Antropólogas de Campo. Buenos Aires, Miño y Dávila Editores, 41-63.

HERMITTE, Esther, 2002, "La observación por medio de la participación”, en S.E. Visakovski y Rosana Guber (comps.), Historia y Estilos del Trabajo de Campo en Argentina. Buenos Aires, Antropofagia, 212-234.

JIMÉNEZ, Alexander, 2002, El Imposible País de los Filósofos. San José, Editorial de la Universidad de Costa Rica.

LEITÓn, Patricia, 2017, "Pobreza total de Costa Rica se mantiene y la extrema se reduce", La Nación, 26 de octubre, disponible en < https://www.nacion.com/economia/indicadores/pobreza-total-de-costa-rica-se-mantiene-y-la-extrema-se-reduce/I6NGELVA6VEIDDY6 3OCQQVIEYM/story/> (última consulta en junio de 2019).

MARKOWITZ, Fernando, 2003, "Sexualizando al antropólogo: implicaciones para la etnografía”, en J.A. Nieto (comp.), Antropología de la Sexualidad y la Diversidad Cultural. Madrid, Talasa, 79-92.

MOLINA, Iván, 2003, Costarricense por Dicha: Identidad Nacional y Cambio Cultural en Costa Rica durante los Siglos XIX y XX. San José, Editorial de la Universidad de Costa Rica.

NASH, Dennison, 1963, "The ethnographer as stranger”, South Western Journal of Anthropology, 19 (2): 149-167.

RODRÍGUEZ AGUILAR, Onésimo Gerardo, 2013, Una Tejita Rata pa’ Evolucionar: Cuadrillas Juveniles y Barrio en Guararí de Heredia. Ciudad de México, Universidad Autónoma Metropolitana de México, tesis doctoral en Ciencias Antropológicas.

RODRÍGUEZ AGUILAR, Onésimo Gerardo, 2017, Aquí Está Todo: Ratas, Evolución y Honor. Cuadrillas Juveniles y Barrio en Costa Rica. San José, Editorial Arlekín.

SANDOVAL, Carlos, 2006, Otros Amenazantes: Los Nicaragüenses y la Formación de Identidades Nacionales en Costa Rica. San José, Editorial Universidad de Costa Rica.

SOLANO, Johel, 2017, "Ola de homicidios: 'hay un desprecio total por la vida'”, crhoy.com, 15 de diciembre, disponible en < https://www.crhoy.com/nacionales/ola-de-homicidioshay-un-desprecio-total-por-la-vida/ > (última consulta en junio de 2019). 